\title{
Laser Shock Processing on Metal
}

\section{Patrice Peyre}

Directeur de Recherche au CNRS, Groupe Laser, PIMM-UMR 8006 CNRS-Arts et Métiers ParisTech, 151 Bd de l'Hôpital, 75013 Paris, France; patrice.peyre@ensam.eu; Tel.: +33-1-7193-6544

Academic Editor: Hugo F. Lopez

Received: 28 September 2017; Accepted: 28 September 2017; Published: 1 October 2017

\section{Introduction and Scope}

Since its invention in the late 1960s, and the pioneering work on metal strengthening in USA during the late 1970s, laser shock processing (LSP) has become a reliable surface treatment for improving the mechanical or corrosion resistance of metallic materials. Moreover, laser-induced shock waves can also be envisaged for the investigation of dense matter's behavior-including phase transformations-under ultra-high strain rate loading (up to $107 \mathrm{~s}^{-1}$ ) using dedicated diagnostics (VISAR, etc.).

This Special Issue on LSP aims at providing a rather exhaustive and up-to-date state of the art on LSP based upon the most recent research works. The following fields are covered in the seven selected papers: materials' behavior and phase transformations under high strain rate (Amadou et al. [1]), new loading conditions with ultra-short pulses (Petronic et al. [2]) surface modifications induced by laser peening including recrystallization effects (Zhou et al. [3]) and warm laser peening (Huang et al. [4], Chen et al. [5]), and novel applications of LSP such as water droplet erosion resistance (Gujba et al. [6]) or impact spot welding (Liu et al. [7]). The wide variety of topics related to LSP highlights the extraordinary dynamism and enthusiasm of the growing international LSP community.

\section{Contributions}

Seven papers have been published in this special issue of Metals on Laser Shock Processing. They can be roughly separated in four distinct topics which are presented here below.

\subsection{LSP-Induced Nano-Recrystallization Effects}

The ability of laser-induced shock waves to generate nano-recrystallization effects was mostly underestimated in the past decades. An example is shown here by Zhou et al. [3] of microstructural modifications at the nanoscale range obtained on a Ti-6Al-4V $(\alpha+\beta)$ titanium alloy. Using the Scherrer-Wilson method for analyzing X-ray diffraction peak broadening, microstrains and average grain sizes of laser-peened diffracting zones were estimated and subjected to TEM microstructural observations. Above three LSP impacts, a minimum grain size of $100 \mathrm{~nm}$ was assumed (compared with 1-2 $\mu \mathrm{m}$ before LSP), which was kept rather constant with subsequent loading steps. An interesting input of TEM was to show that multiple laser impacts tend to promote more homogeneous nano-grain distributions, and that $\alpha$ and $\beta$ phases exhibit specific plastic deformation modes (regular dislocation lines and mechanical twins for $\alpha$ and dense and tangled dislocations on $\beta$ ).

\subsection{Warm Laser Peening Applied to Aluminum Alloys}

In its usual form, laser peening is carried out at room temperature. However, recent developments have shown a possible benefit of performing LSP treatments at elevated temperature, mostly to combine the benefits of laser peening and dynamic strain aging. Two papers have been selected to put a focus on this advanced surface strengthening technique. They provide interesting insights into the beneficial 
effects of temperature on laser-shock-induced plastic deformations. Considering LSP temperature ranges up to $160^{\circ} \mathrm{C}$ and a 6061 (A10.9Mg0.6Si) alloy, warm laser peening (WLP) trials were carried out with $2 \mathrm{~mm}$ diameter impacts, a 50\% overlap, and a glass confining medium [3]. Such WLP trials evidence a $20 \%$ decrease of surface compressive stresses, but deeper affected layers and large hardening effect (up to $+55 \% \mathrm{HV}$ for a WLP at $130{ }^{\circ} \mathrm{C}$ ). Microstructural TEM and optical microscopy $(\mathrm{OM})$ analysis reveal a higher dislocation density and more pronounced grain refinement when LSP is performed at elevated temperature. Many dislocations tangled to strengthening precipitates are also shown, which are assumed by Huang et al. [4] to be beneficial for improving residual stress stability. This last aspect was confirmed for a similar WLP procedure by Chen et al. [5], considering an A356 (Al7Si0.3Mg) cast aluminum alloy. After a $220^{\circ} \mathrm{C}-100 \mathrm{~min}$ thermal treatment, WLP samples exhibited more stable residual stress fields than room temperature peening. Due to the enhanced dynamic strain aging and grain refinement effect, hardness levels were also found to be systematically higher and more stable than after conventional laser peening.

\subsection{New Applications and Loading Conditions for Laser-Shock Processing}

Novel potential applications have recently emerged either for laser peening [6], or more broadly, for laser-induced shock waves [7]. Besides, new LSP loading conditions like those using ultra-short pulses in the picosecond [2] or femtosecond range have appeared.

The mitigation of water droplet erosion (WDE) with laser peening was addressed by Gujba et al. [6] using the MIC-Lawrence Livermore laser facility, delivering squared laser impacts. The main application envisaged is the leading edge of Ti-6Al-4V compressor blades in gas turbines. Considering cumulative mass loss during water erosion for impact speeds of 150 to $350 \mathrm{~m} / \mathrm{s}$, the comparison between laser peened and as-machined samples (T-shaped flat or Airfoil-like) does not indicate a beneficial effect of LSP. This is mostly attributed to the limited work-hardening imparted by LSP, in spite of deep and intense residual stresses. Indirectly, such a research work provides interesting insight into the physical mechanisms involved in WDE, which are not directly controlled by fatigue behavior.

Apart from the well-known strengthening effect of laser peening, laser-induced shock waves can also be envisaged for generating spot-welding, especially when considering dissimilar alloys such as titanium and copper. The original work by Liu et al. [7] demonstrates the feasibility of Ti-Cu joining by laser induced spot welding, through the dynamic collision between a thin laser-accelerated titanium flyer plate and a copper substrate, separated by an optimized stand-off distance. An interesting point to notice is the need of jetting formation behind the flyer plate to provide a cleaned impact surface by removing contaminants and ensuring optimum contact between Ti and $\mathrm{Cu}$. With optimized LSP conditions, wavy interfaces can be obtained, similar to those shown in conventional explosive welding. Such interfaces are shown to favor anchoring effects and improve bond strengths.

Even though the use of very short pulses is not common in the field of LSP applications, Petronic et al. [2] shows that 170 ps pulses carried out with a large number of local impacts (up to 200) can generate interesting microstructural modifications and resulting hardness levels on a Ni-based superalloy. Even if some questions remain unanswered about the precise thermal + mechanical loading submitted to surfaces, this work opens a new range of investigations on new ranges of materials' dynamic loading.

\subsection{Phase Transformation under Severe Laser-Shock Loading}

Following earlier works, the kinetics of phase transformation on iron was investigated by Amadou et al. [1] under laser-induced ultra-high strain rate, using a dedicated beam smoothing system to deliver a uniform spatial loading. Using Doppler velocimetry diagnostics and severe loading conditions (several tenths of $\mathrm{GPa}, \mathrm{d} \varepsilon / \mathrm{d} t \approx 10^{7} \mathrm{~s}^{-1}$ ), useful data have been measured such as elastic-plastic transitions or $\alpha-\varepsilon$ phase transformation in terms of shock pressure thresholds. One of the most interesting inputs of this paper is the integration of real physical deformation mechanisms 
such as twinning or dislocation slip into constitutive laws to provide a predictive modelling of shock propagation and phase transformation kinetics. Such an approach appears to be particularly important because there is still a lack a reliable and physically consistent constitutive equations to model real-time behavior of laser-impacted materials and resulting residual effects.

\section{Conclusions}

In the seven original research papers presented in this special issue on LSP, the reader will benefit from a representative overview on current LSP works, which demonstrate the versatility and capability of laser-induced shock waves to reinforce or probe the dense matter. Various pure metals ( $\mathrm{Fe}$ ) or alloys (C263 Ni-base, A356 and 6061 aluminum alloys, Ti-6Al-4V, Cu) have been considered, thus confirming the wide range of possible applications for LSP. Moreover, as shown by at least three papers presented in this review, many questions remain, especially concerning microstructural modifications induced by laser peening surface treatment, especially including dislocations' sub-structure and their relation to hardening levels or residual stress distribution. It is sure that these seven papers will contribute to the dissemination of novel ideas and concepts related to LSP.

Conflicts of Interest: The author declares no conflict of interest.

\section{References}

1. Amadou, N.; Brambrink, E.; de Rességuier, T.; Ousmane Manga, A.; Aboubacar, A.; Borm, B.; Molineri, A. Laser-Driven Ramp Compression to Investigate and Model Dynamic Response of Iron at High Strain Rates. Metals 2016, 6, 320. [CrossRef]

2. Petronic, S.; Sibalija, T.; Burzic, M.; Colic, K.; Milovanovic, D. Picosecond laser shock peening of Nimonic 263 at $1064 \mathrm{~nm}$ and $532 \mathrm{~nm}$ wavelength. Metals 2016, 6, 41. [CrossRef]

3. Zhou, W.; Ren, X.; Liu, F.; Ren, Y.; Li, L. Nanocrystallization effects in the Duplex Ti-6Al-4V Alloy processed by multiple laser shock peening. Metals 2016, 6, 297. [CrossRef]

4. Huang, S.; Wang, Z.; Sheng, J.; Agyenim-Boateng, E.; Liu, M.; Yang, X.; Zhou, J. Residual Stress Distribution and Microstructure Evolution of AA 6061-T6 Treated by Warm Laser Peening. Metals 2016, 6, 292. [CrossRef]

5. Chen, H.; Zhou, J.; Sheng, J.; Meng, X.; Huang, S.; Xie, X. Effects of Warm Laser Peening on Thermal Stability and High Temperature Mechanical Properties of A356 Alloy. Metals 2016, 6, 126. [CrossRef]

6. Gujba, A.K.; Hackel, L.; Medraj, M. Water droplet Erosion of laser-shock peened Ti-6Al-4V. Metals 2016, 6, 262. [CrossRef]

7. Liu, H.; Gao, S.; Yan, Z.; Li, L.; Sun, X.; Sha, C.; Shen, Z.; Ma, Y.; Wang, X. Investigation of a novel laser impact spot welding. Metals 2016, 6, 179. [CrossRef] 